\title{
Real Time Traffic Splitting and Efficient Flooding Mechanism in LSRP
}

\author{
Sheetal Dadhich \\ ME (CSE) $2^{\text {nd }}$ Year \\ NBNSCOE, Solapur \\ Maharashtra, India
}

\author{
S.S. Joshi \\ Asst. Professor \\ NBNSCOE, Solapur \\ Maharashtra, India
}

\begin{abstract}
From last many years traffic in internet is increasing very rapidly. But as internet in growing up we required to maintain quality and have to increase the efficiency of network. Also we should concentrate on efficient mechanism of flooding, load balancing \& resource utilization. In today's internet world mostly Link state routing protocols like Open Shortest Path First (OSPF) routing protocol is used which is based on link weighs, as optimizing link weight in OSPF to the group traffic is well-know NP-Hard problem. In the consideration of current situation of the network we introduce a new method called Real time traffic splitting \& efficient flooding mechanism in network with the help of OSPF. We will reduce the time required to compute the weight on link and find the best links to forward the packet within short time.

The concept is to first minimize link state advertisement packets \& split the traffic over first few multiple shortest paths to reach to destination. As traffic increases our protocol automatically sends packet through next shortest path present in the network. We can increase the performance of network $\&$ achieve optimal traffic engineering. As compare with the OSPF packet forwarding mechanism is same which is destination based \& hop by hop forwarding just difference is in splitting mechanism.
\end{abstract}

\section{General Terms}

IP Wired Network.

\section{Keywords}

Open Shortest Path First (OSPF), Efficient flooding, Traffic Engineering.

\section{INTRODUCTION}

Now a days to find the shortest path from source to destination node in any sized network Link state routing protocols are commonly used, protocols such as Open shortest path first (OSPF) and Intermediate system to Intermediate system (IS-IS). We know, from last few years the importance of IP network has surprisingly increased. Because increasing use of network, number of unpredicted connections is increased so network is unable to manage traffic. Once the network protocol fails to manage traffic; automatically question arrives for quality of service. To manage the traffic, we have to watch on link capacity, current load on link \& reduce to transfer unnecessary packets like LSA. Protocols like OSPF and IS-IS that selects the path based in link weights, with these protocols computing the right link weight is NP-hard [1]

OSPF has its own packet forwarding mechanism: Hop-byHop and destination based. It split the traffic over shortest path based from source to destination. If traffic increases then it is difficult to transfer the packets from source to destination through single route. Because of that QoS is decreased and TE issues are increased. We are referred traffic engineering as improving network performance and making efficient use of resources requires adapting the routing of traffic. The important challenging part in network is to manage an IP network with the help of existing protocols. To manage network in sense of managing the load on a link and utilization of resources is an important issue. Also to optimize traffic engineering (TE) is main challenge. For managing a routing protocol if the complexity were not a concern then other approaches could use to achieve optimal traffic engineering. One possibility in multicommodity flow type of routing, where an optimal traffic distribution is realized by dividing an arbitrary fraction of traffic over many paths [2]. This can be supported by a flexible way to split traffic over shortest path. Along with that if we reduce the unnecessary traffic like link state advertisement packets from network it helps to achieve efficient flooding mechanism in OSPF

This thesis introduced a new routing protocol that accept this challenge and try to achieve optimal traffic engineering, real time traffic splitting and efficient flooding mechanism in link state routing protocols. To develop this protocol first, we should know the three main components which are to be used to design a link state routing protocol. First is computation of weight, second is traffic splitting and third is packet forwarding. The set of link weights computes through a periodic and centralized optimization in weight computation method. In traffic splitting each router decides traffic splitting ratio among its outgoing links for every destination with the help of link weights. With the help of these three components of link state routing protocols we were tried to develop a new link state routing mechanism named Real time traffic splitting(RTTS).

The name itself gives the basic idea behind the project. In our RTTS routing protocol weight computation and packet forwarding mechanism are same but the difference is in traffic splitting. In this protocol we will reduce LSA packets \& split the traffic over multiple shortest paths to forward packet from one source to destination.

\section{LITERATURE SURVEY}

Table 1: Literature survey

\begin{tabular}{|c|c|c|}
\hline $\begin{array}{c}\text { Name of } \\
\text { Mechanism }\end{array}$ & Concept defined & \multicolumn{2}{|c|}{ Limitations } \\
\hline $\begin{array}{c}\text { OSPF (mid } \\
\text { of 1980) }\end{array}$ & $\begin{array}{l}\text { 1. It uses Shortest } \\
\text { path algorithm } \\
\text { to reach } \\
\text { destination. [1] }\end{array}$ & $\begin{array}{c}\text { 1. The chosen paths are } \\
\text { not robus under } \\
\text { change in traffic or } \\
\text { network state.[7] }\end{array}$ \\
2. Use Flooding & 2. Offered traffic is well- \\
\hline
\end{tabular}




\begin{tabular}{|c|c|c|}
\hline & $\begin{array}{l}\text { mechanism to } \\
\text { synchronize } \\
\text { routing } \\
\text { database.[1] }\end{array}$ & $\begin{array}{l}\text { known NP Hard } \\
\text { Problem.[1] } \\
\text { 3. Less utilization of } \\
\text { resources. [4] } \\
\text { 4. Does not think about } \\
\text { the load on link. [1] } \\
\text { 5. This protocol is not } \\
\text { used for arbitrary } \\
\text { traffic pattern. [5] } \\
\text { 6. No any solution of } \\
\text { flooding mechanism. }\end{array}$ \\
\hline ECMP & $\begin{array}{l}\text { 1. It split traffic } \\
\text { over equal cost } \\
\text { multiple paths. } \\
\text { [8] } \\
\text { 2. Tried to utilize } \\
\text { resources. [8] }\end{array}$ & $\begin{array}{l}\text { 1. Not able to split traffic } \\
\text { equally. [2] } \\
\text { 2. Does not think about } \\
\text { the load on link. [6] } \\
\text { 3. This protocol is not } \\
\text { used for arbitrary } \\
\text { traffic pattern. [2] } \\
\text { 4. No any solution of } \\
\text { flooding mechanism. }\end{array}$ \\
\hline ECMP & $\begin{array}{l}\text { 1. It split traffic } \\
\text { over equal cost } \\
\text { multiple paths. } \\
\text { [8] } \\
\text { 2. Tried to utilize } \\
\text { resources. [8] }\end{array}$ & $\begin{array}{l}\text { 1. Not able to split traffic } \\
\text { equally. [2] } \\
\text { 2. Does not think about } \\
\text { the load on link. [6] } \\
\text { 3. This protocol is not } \\
\text { used for arbitrary } \\
\text { traffic pattern. [2] } \\
\text { 4. No any solution of } \\
\text { flooding mechanism. }\end{array}$ \\
\hline DEFT & $\begin{array}{l}\text { 1. This is link } \\
\text { based protocol } \\
\text { [2] } \\
\text { 2. Better than } \\
\text { OSPF in } \\
\text { minimizing the } \\
\text { sum of link } \\
\text { cost. [2] }\end{array}$ & $\begin{array}{l}\text { 1. DEFT can split traffic } \\
\text { arbitrarily over any } \\
\text { paths. [1] } \\
\text { 2. Database } \\
\text { Synchronization is a } \\
\text { big issue. } \\
\text { 3. No any solution of } \\
\text { flooding mechanism. }\end{array}$ \\
\hline PEFT & $\begin{array}{l}\text { 1. PEFT is path } \\
\text { based protocol } \\
\text { \& It split traffic } \\
\text { along all the } \\
\text { paths reaches to } \\
\text { destination. [1] } \\
\text { 2. PEFT provably } \\
\text { achieve optimal } \\
\text { traffic } \\
\text { engineering } \\
\text { while retaining } \\
\text { the simplicity } \\
\text { of hop by hop } \\
\text { forwarding. [1] }\end{array}$ & $\begin{array}{l}\text { 1. In PEFT it split traffic } \\
\text { on the basis of number } \\
\text { of paths reaches to } \\
\text { destination. [1] } \\
\text { 2. Database } \\
\text { Synchronization is big } \\
\text { issue. } \\
\text { 3. No any solution of } \\
\text { flooding mechanism. }\end{array}$ \\
\hline
\end{tabular}

\section{METHODOLOGY}

To achieve above objective, following methodology is proposed. Consider a wired IP network as directed graph $\mathrm{G}=$ $\langle\mathrm{V}$; $\mathrm{E}\rangle$, where $\mathrm{E}$ is the set of links and $\mathrm{V}$ is the set of vertices (or node). As shown in figure 1.

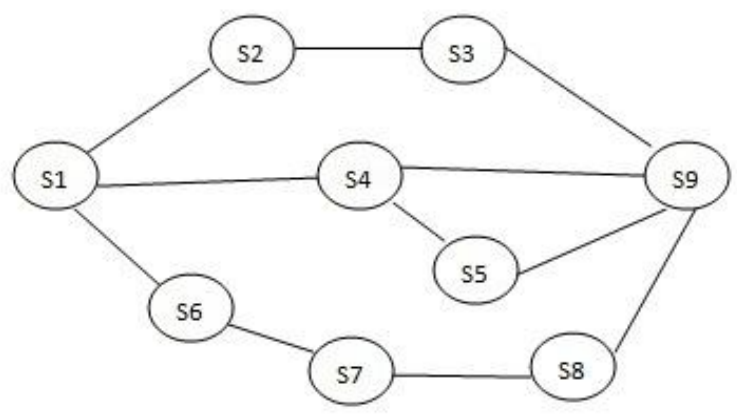

Figure 1: An IP Network

We can consider $\mathrm{S} 1$ as a source and S9 is destination where the link $(a, b)$ has traffic capacity tCa,b. Suppose $\mathrm{S} 1$ wants to send packet to $S 9$, with the help of shortest path algorithm. $\operatorname{Sd}(a ; b)=\{\operatorname{minCo}\{(p): a->b\}--$ if there is a path from $a$ to $b$ $\infty$---------------- otherwise

Table 2 Summery of Key notation

\begin{tabular}{|l|l|}
\hline PARAMETER & PARTICULAR \\
\hline $\mathrm{wa}, \mathrm{b}$ & Assigned weigh to link $(\mathrm{a}, \mathrm{b})$ \\
\hline $\mathrm{tfa}, \mathrm{b}$ & Traffic Flow on link $(\mathrm{a}, \mathrm{b})$ \\
\hline $\mathrm{tfta}, \mathrm{b}$ & $\begin{array}{l}\text { Traffic Flow on link }(\mathrm{a}, \mathrm{b}) \text { destined to node } \\
\mathrm{Sj}\end{array}$ \\
\hline $\mathrm{tfta}$ & $\begin{array}{l}\text { Total incoming traffic flow (destined to } \mathrm{Sj}) \\
\text { at a }\end{array}$ \\
\hline tca,b & Traffic capacity of link $(\mathrm{a}, \mathrm{b})$ \\
\hline tc $\sim \mathrm{a}, \mathrm{b}$ & Required traffic capacity of link $(\mathrm{a}, \mathrm{b})$ \\
\hline $\mathrm{tD}(\mathrm{s}, \mathrm{t})$ & $\begin{array}{l}\text { Traffic demand from source Si to } \\
\text { destination } \mathrm{Sj}\end{array}$ \\
\hline$d(a, b)$ & Shortest path from a to b \\
\hline$\tilde{\omega}(\mathrm{p})$ & Alternative path \\
\hline$R i$ and $R j$ & Route $\mathrm{i}$ and route $\mathrm{j}$ \\
\hline
\end{tabular}

We will divide our project in to two different modules, First, Decrease the LSA packets \& Second, Split the traffic. For reducing LSA packet overhead we will take minimum spanning tree of our IP network then we will get the node which have degree one to other nodes. We will add one more degree to those nodes who have only one link connected to other spanning tree. Second, it will find out first two shortest path and sends the traffic through route ri and route $\mathrm{rj}$. If the traffic is more on any of these links then source node S1 will go for third shortest path. With consideration of same example $\mathrm{S} 1$ is source and S9 is destination, first shortest path is S1-> $\mathrm{S} 4 \rightarrow \mathrm{S} 9$ and another one is $\mathrm{S} 1 \rightarrow \mathrm{S} 2 \rightarrow \mathrm{S} 3 \rightarrow \mathrm{S} 9$. Now consider if traffic is more on route rj, in our example $\mathrm{S} 1 \rightarrow$ $\mathrm{S} 2 \rightarrow \mathrm{S} 3 \rightarrow \mathrm{S} 9$ then traffic will shift to third shortest path which is $\mathrm{S} 1 \rightarrow \mathrm{S} 4 \rightarrow \mathrm{S} 5 \rightarrow \mathrm{S} 9$. The capacity of any link is considered as tCa,b and the current load means current flow is considered as tfa,b on each link $(a, b)$. If we need to maintain traffic engineering then out link cost function should be $0<\mathrm{tCa}, \mathrm{b} / \mathrm{tfa}, \mathrm{b}>1$. It means our objective for traffic engineering is to minimize the maximum the utilization of link (a.b).

The most important issue in our protocol is we need to calculate link weight at runtime and then split the traffic again check whether traffic is more on link if not continue with the transfer. As suggested in [2] for computation of link weight and link weight update, we refer those two algorithms as follows. For Link Weights Calculation we have to set our flow up to necessary capacity of link means, algorithm for computing the necessary traffic capacity tcN.

While tfa, $\mathrm{b} \neq \mathrm{tc}^{\mathrm{N}}{ }_{\mathrm{a}, \mathrm{b}}$ 
do

$\mathrm{w} \leftarrow$ Link_Weight_Updates(f)

tf $\leftarrow$ Traffic_Splitting(w)

end while

Return w

Then, the procedure increases the weight of each link $(a, b)$ if the traffic flow exceeds the necessary traffic capacity, or decreases it otherwise. The parameter is a positive step-size, which can be constant or dynamically adjusted. For updating of link weight of any link $(a, b)$

do

$\mathrm{nWa}, \mathrm{b} \leftarrow \mathrm{cWa} ; \mathrm{b}-\mu\left(\mathrm{tc}_{\mathrm{a}, \mathrm{b}}^{\mathrm{N}}-\mathrm{tf}_{\mathrm{a}, \mathrm{b}}\right)$

end for

Return new link weights nW

After updating traffic we have to split the traffic through first two shortest paths $\delta(a, b)$ as per our example.

To achieve optimal traffic engineering in IP network following approach is used:

1. Use hello packets for synchronization of database in network for calculating shortest path.

2. Network entropy maximization method is used for calculating link weight and traffic splitting function.

3. Multi-commodity method is used to find out multiple shortest path from source to destination.

4. Use minimum spanning tree method to reduce flooding of LSA packets.

5. Finally compare MSPF, OSPF and IS-IS protocols with different parameters like delay, throughput and packet delivery ratio.

\section{CONCLUSION}

In the consideration of current situation of the network we introduce a new method called Real time traffic splitting \& efficient flooding mechanism in network with the help of OSPF. We will reduce the time required to compute the weight on link and find the best links to forward the packet within short time. This dissertation work can prove that, this new protocol is having better performance than OSPF and ISIS with considering Delay, Throughput and Packet delivery ratio parameters.

\section{REFERENCES}

[1] Mr. R.S. Dayama and Prof. S.P. Pingat "Optimal TE in LSRP”, IJCA, Vol 68-NO.18 April 2013

[2] D. Xu, M. Chiang, and J. Rexford, DEFT: Distributed exponentially weighted flow splitting, in INFOCOM07, Anchorage, AK, May 2007.

[3] Dahai Xu, Member, IEEE, Mung Chiang, Senior Member, Link-State Routing With Hop-by-Hop Forwarding Can Achieve Optimal Traffic Engineering, IEEE, and Jennifer Rexford, Senior Member, IEEE, Fellow, ACM, 2011.

[4] Seung Hwan Lee and Seung Hyong Rhee Efficient for Reliability in Link state routing protocol IEEE 978-14673-4828-7/12/ 2012.

[5] B. Fortz and M. Thorup, Increasing Internet capacity using local search, Computational Optimization and Applications, vol. 29, no. 1, pp. 1348, 2004.

[6] Antic, M. Sch. of Electr. Eng., Belgrade Univ., Belgrade, Serbia Two phase load balanced routing using OSPF, , IEEE Journal Jan 2010.

[7] Shekhar Srivastava, Gaurav Agrawal, Michal Pioro and Deepa Medhi, Determining Link Weight System under Various Objectives for OSPF Networks using a Lagrangian Relazation-Based Approach, IEEE transactions on Network and servicemanagement, 2005.

[8] Jessica H. Fong, Anna C. Gilbert, Sampath Kannan, Martin J. Strauss, Better Alternatives to OSPF Routing, Dec 2004

[9] Ari Lappetelainen, Equal Cost Multipath Routing in IP Networks, Faculty of Electronics, Communications and Automation, March 2011. 